Article

\title{
Long-Term Impact of Sediment Deposition and Erosion on Water Surface Profiles in the Ner River
}

\author{
Tomasz Dysarz *, Ewelina Szałkiewicz and Joanna Wicher-Dysarz \\ Department of Hydraulic and Sanitary Engineering, Poznan University of Life Sciences, ul. Wojska Polskiego 28, \\ 60-637 Poznan, Poland; ewelszal@up.poznan.pl (E.S.); jwicher@up.poznan.pl (J.W.-D.) \\ * Correspondence: dysarz@up.poznan.pl; Tel.: +48-61-846-6586, Fax: +48-61-848-7726
}

Academic Editor: Karl-Erich Lindenschmidt

Received: 2 December 2016; Accepted: 22 February 2017; Published: 27 February 2017

\begin{abstract}
The purpose of the paper is to test forecasting of the sediment transport process, taking into account two main uncertainties involved in sediment transport modeling. These are: the lack of knowledge regarding future flows, and the uncertainty with respect to which sediment transport formula should be chosen for simulations. The river reach chosen for study is the outlet part of the Ner River, located in the central part of Poland. The main characteristic of the river is the presence of an intensive morphodynamic process, increasing flooding frequency. The approach proposed here is based on simulations with a sediment-routing model and assessment of the hydraulic condition changes on the basis of hydrodynamic calculations for the chosen characteristic flows. The data used include Digital Terrain Models (DTMs), cross-section measurements, and hydrological observations from the Dabie gauge station. The sediment and hydrodynamic calculations are performed using program HEC-RAS 5.0. Twenty inflow scenarios are of a 10-year duration and are composed on the basis of historical data. Meyer-Peter and Müller and Engelund-Hansen formulae are applied for the calculation of sediment transport intensity. The methodology presented here seems to be a good tool for the prediction of long-term impacts on water surface profiles caused by sediment deposition and erosion.
\end{abstract}

Keywords: sediment routing; deposition forecasting; numerical simulations; the Ner River

\section{Introduction}

The ideas presented here are related to sediment transport impact on changes in bed and water surface profiles. The purpose of the paper is to find the most reliable method for forecasting this process, taking into account two main uncertainties involved in sediment transport modeling. These are the lack of knowledge regarding future flows, and uncertainty with respect to sediment transport formulae that should be chosen for simulations. The methodology applied enables the assessment of the sediment accumulation influence on flood hazards and other phenomena depending on channel capacity.

Sediment transport and the processes of sedimentation and erosion have become a very popular area of scientific investigation (see, for example, References [1-8]). Taking into account the spatial scale of the problem, the complexity of channel networks, and processes analyzed, mathematical models are frequently used in such research. Because the areas of sediment transport and sediment modeling are not yet well known, the models have to be completed with a number of empirical assumptions (see, for example, References [9-13]). Successful modeling is strongly dependent on the choice of sediment transport formula determining the transport intensity. Hence, it is one of the most important uncertainty sources in the forecasting of this process and its consequences $[2,14]$. The second source is more common in any forecasting of flow phenomena. There is no or incomplete knowledge about the future inflows to the river, reservoir, or any other water system. In the case of sediment transport, characterized by slow changes and long duration, this problem is of real significance. Forecasting 
of flows in the time frame necessary for modeling of sediment transport is impossible. Hence, only hypothetical scenarios can be analyzed and statistically processed.

Another important aspect of the research presented here is the impact of the deposition and erosion on flow process and important hydraulic parameters in a natural river, e.g., References [2,15]. The sediment transport changes the capacity of the river channel. From a water management point of view, the most important may be water surface elevations and inundation areas. They depend on channel capacity, but this dependence is not direct. Hence, prediction of the described process with its entire complexity requires the application of sophisticated mathematical models with several empirical or subjective assumptions $[10,12,16,17]$, which may be additional sources of uncertainty.

In Poland, the problem discussed here has not often been analyzed in the context presented above. In the scientific literature, there are relatively few analyses, which link natural changes in the channel conveyance with elements determining the use of the river, e.g., flood hazard, shipping, etc. This is one of the reasons why we decided to address the problem.

\section{Study Site Description}

The Ner Basin area is situated in the Central Greater Poland and Central Poland climatic regions. The catchment area and boundaries are shown in Figure 1 and marked in orange. The river Ner is a right tributary to the river Warta. Both rivers, the Ner and the Warta, are marked as blue lines in Figure 1. The total area of the Ner Basin is $1835 \mathrm{~km}^{2}$, while the length of the river is $134 \mathrm{~km}$. The Ner flows through two voivodships, namely Greater Poland and Łódzkie. The sources of the river are located in the town of Łódź in the area of the Widzew District [18]. The outlet is in km $444+400$ of the Warta River, near the village of Majdany [19]. The reach of the Ner River selected for the presented analyses is marked with a pink polygon in Figure 1.

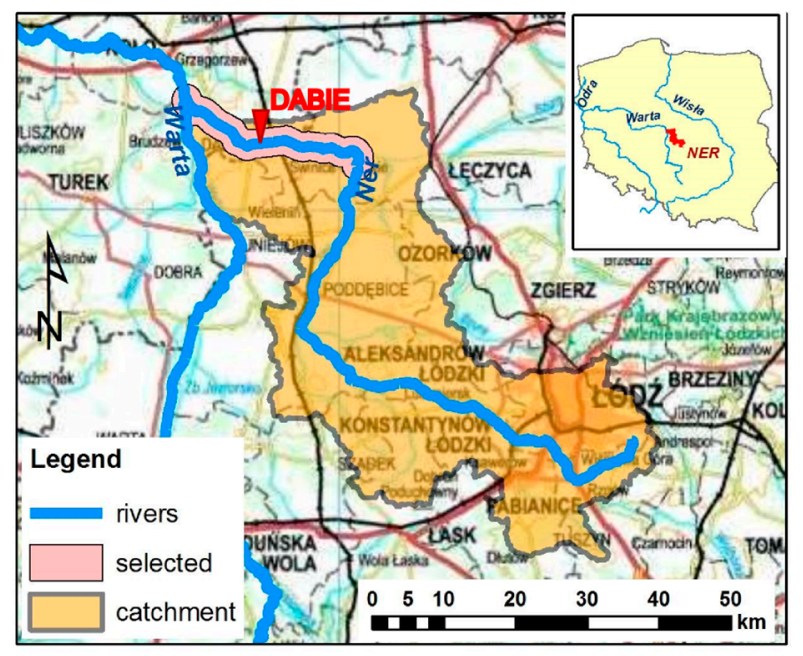

Figure 1. Location of the Ner River basin and selected reach of the channel.

According to the physico-geographic division proposed by Kondracki [20], the Ner Basin area is situated in the following macroregions: Acclivity of Southern Masovia, the lowlands of Southern Greater Poland, and the lowlands of Central Masovia. The area has a "lowland" character. The absolute altitudes of the terrain vary from 92.50 to $279.8 \mathrm{~m}$ a.s.l. The mean slope of the basin is $1.17 \%$. The area is mainly covered by arable land, which occupies $63.35 \%$ of the total basin area. The other forms of land use are forests $(14.2 \%)$, greenery $(10.8 \%)$, and urbanized land $(11.4 \%)$. The total area of the lakes is $4.5 \mathrm{~km}^{2}$, which, with respect to the total basin area, gives a lake index of $0.25 \%$. The density of the river network is $1.59 \mathrm{~km} \cdot \mathrm{km}^{-2}$.

The graphs presented in Figure 2 characterize the variability of flow in the Ner River. They are composed on the basis of data from the Dabie gauge station. The first graph (Figure 2a) presents 
annual minimum, mean, and maximum flows over the period of 1964-2013. They are denoted as green squares, blue lines, and red dots, respectively. The greatest floods observed in this time are denoted additionally by year of occurrence (in red). The second graph (Figure $2 b$ ) presents ordinary variability of flow within a year. This plot is also prepared on the basis of data for the period of 1964-2013. The green, blue, and red bars represent averages of minimum, mean, and maximum flows observed in particular months, respectively. Additionally, the extreme values for these characteristics, minimum and maximum, are shown as confidence intervals in the form of dashed lines. The floods presented in Figure $2 \mathrm{a}$ are also denoted in Figure $2 \mathrm{~b}$.

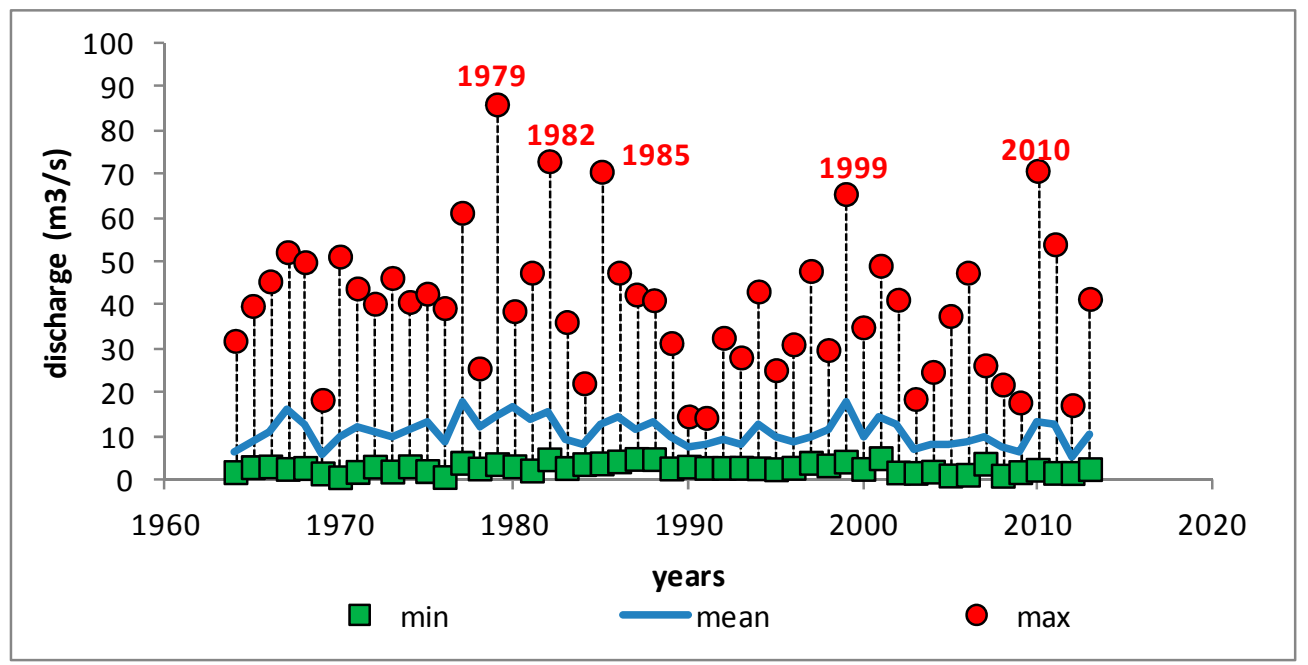

(a)

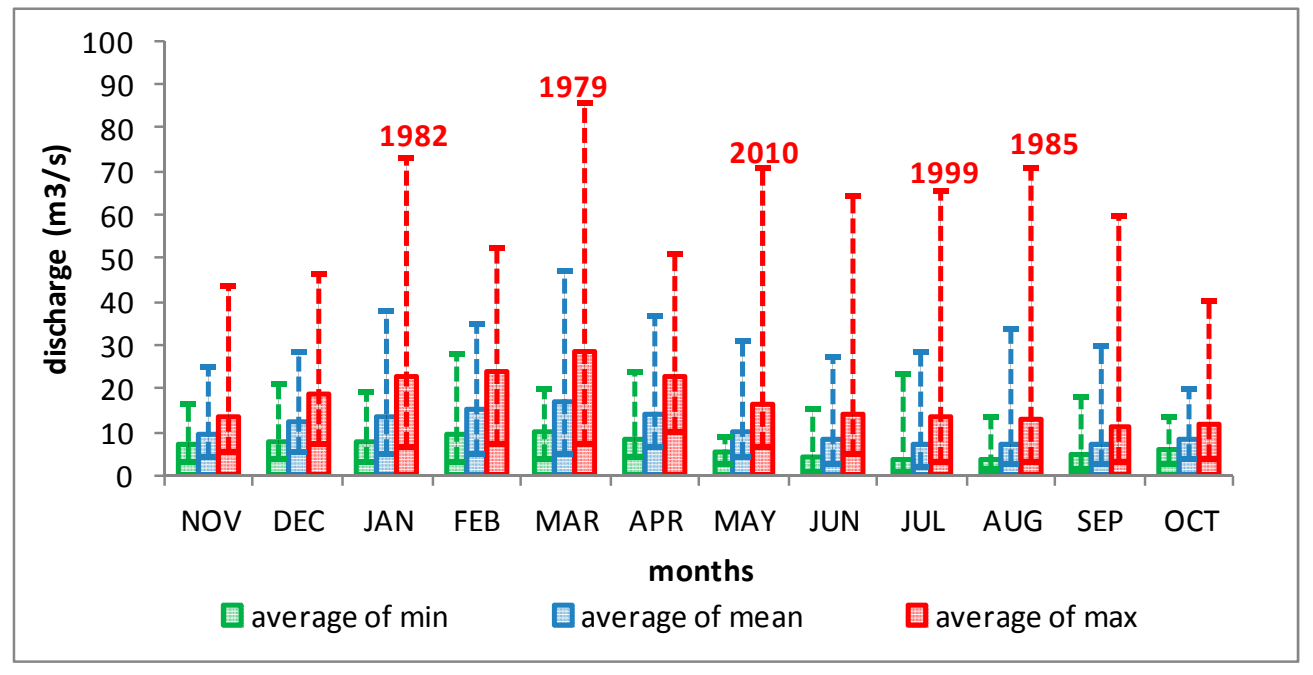

(b)

Figure 2. Characteristics of flow variability in the Dabie gauge station for the period of 1964-2013. (a) annual minimum, mean, and maximum flows; (b) monthly averages of minimum, mean, and maximum flows with extremes.

The Ner River is characterized by snow and rain regime of supply, with a single maximum (March, April) and a single minimum (July-September) in a year. The annual mean flow of the Ner River in the Dabie profile, in the period of 1961-2013 [21], was $10.93 \mathrm{~m}^{3} \cdot \mathrm{s}^{-1}$, with a minimum of $0.7 \mathrm{~m}^{3} \cdot \mathrm{s}^{-1}$ and a maximum of $86.0 \mathrm{~m}^{3} \cdot \mathrm{s}^{-1}$. The extreme floods may occur all year, as shown in Figure $2 \mathrm{~b}$. In the past, there was a period of very large floods in 1979-1985, when the three biggest floods occurred. The estimated values of the maximum flows came to $86.0 \mathrm{~m}^{3} \cdot \mathrm{s}^{-1}$ in $1979,73.0 \mathrm{~m}^{3} \cdot \mathrm{s}^{-1}$ in 1982 , 
and $70.6 \mathrm{~m}^{3} \cdot \mathrm{s}^{-1}$ in 1985. Similar floods were observed in 1999 and 2010, when the maximum flows reached values of $65.5 \mathrm{~m}^{3} \cdot \mathrm{s}^{-1}$ and $70.8 \mathrm{~m}^{3} \cdot \mathrm{s}^{-1}$, respectively.

Earlier observations of this system indicated intensive sediment transport and deposition (Figure 3) [22]. The selected river reach was regulated by construction works, aimed at improving channel capacity (in 1983). The design of the regulated bed in 1983 is very simple. It was assumed that the river reach would have a single slope and regular shape. In Figure 3, this bed is presented as a black straight line. The design was implemented but it is not known how accurate the final regulation was in comparison with the design. However, it is assumed that the uncertainty is small enough to make the qualitative comparisons necessary to explain the essence of the problem analyzed. After 20 years, in 2003, the capacity of the channel was almost completely reduced comparing with the state of the channel in 1983 year. Changes in bed elevation reached a magnitude of about $1 \mathrm{~m}$ and were uniformly distributed along the channel. In 2007, the river reach was regulated once again and hydraulic conditions were restored. In Figure 3, the bed profiles for these three characteristic moments are compared. The data used to compose the presented graph are taken from past designs of river regulations and documents reporting the hydraulic conditions in the river [22]. The data are not georeferenced, and, therefore, it is difficult to adopt them in current research. However, the comparison well shows the problem in this river reach.

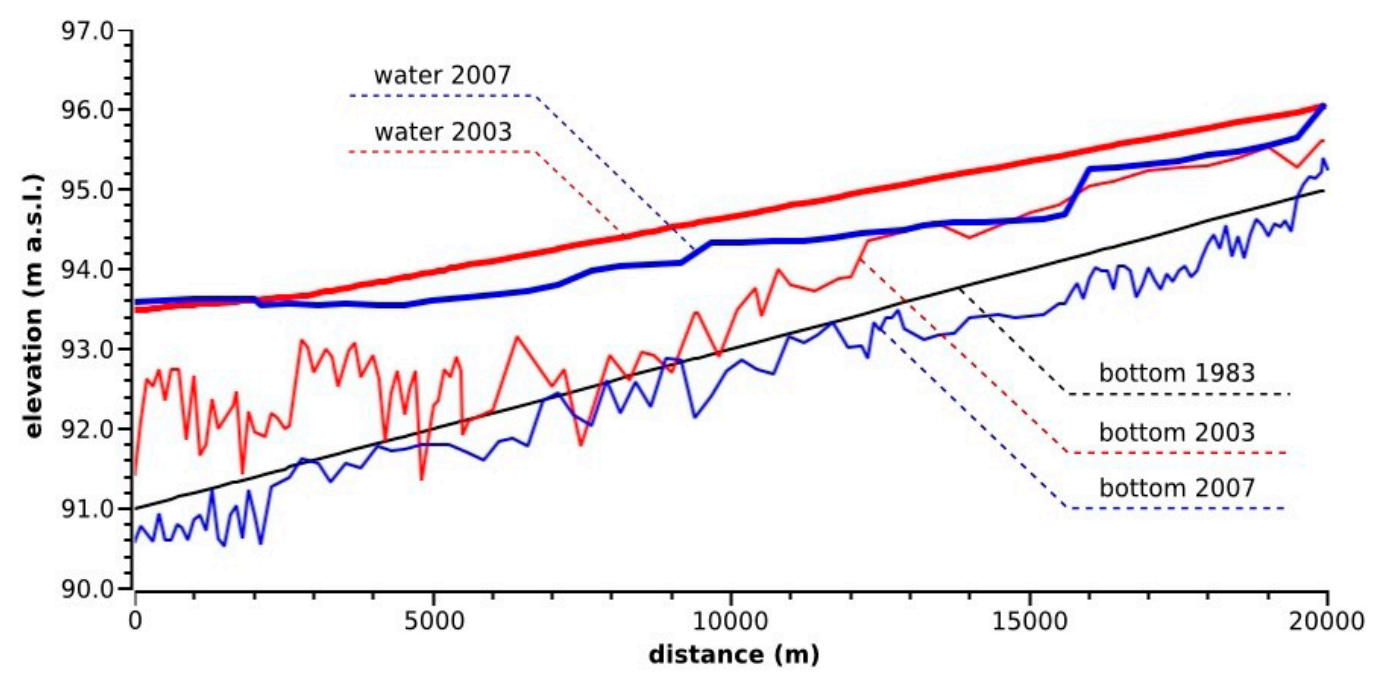

Figure 3. Comparison of bottom and water surface profiles observed in 1983, 2003, and 2007.

The graph in Figure 3 shows huge differences between bed elevations measured in 1983 and 2003. The changes induced by sediment transport are not uniform. In some separated cross-sections, erosion may be noticed, but, in general, the sediment deposition is about $1 \mathrm{~m}$. It is also important to indicate that the changes are rather uniformly distributed. Taking into account the length of this period (20 years), and the uncertainty related to the lack of other observations, we may expect the bottom to rise about $0.5-1.0 \mathrm{~m}$ over a 10 -year period.

It is also important to note that numerous environment protection zones are present in the vicinity of the selected river reach. Some of them are the Nature 2000 areas. In the Ner Valley, there are two kinds of such zones, namely the Special Protection Area (SPA) and the Special Area of Conservations $(\mathrm{SAC})$. Another protection zone is the Ecological Corridors of the Warta and the Nida Valleys.

\section{Materials and Methods}

In the research, three methods are used: (1) spatial data analyses; (2) simulation with a hydrodynamic model; and (3) statistical analyses. The methods and tools for spatial data analyses are implemented during the preparation of the model; they are mainly used for processing the 
geometry of the river reach and the topography of the river valley. Such an approach requires that the bathymetry of the river channel, determined on the basis of ISOK measurements [23] (Polish: ISOK = Informatyczny System Osłony Kraju przed nadzwyczajnymi zagrożeniami, English: IT system of the Country's Protection Against Extreme Harazds), is linked with DTM obtained from CODGiK [24] (Polish: CODGiK = Centralny Ośrodek Dokumentacji Geodezyjnej i Kartograficznej, English: Main Documentation Centre of Geodesy and Cartography). For this purpose, the standard ArcGIS software [25] is used with the free extension GeoRAS [26]. Some of the work is also done with the help of RAS Mapper, which is a part of the HEC-RAS package [27]. At this stage, the basic techniques of spatial data editing are used, as well as advanced spatial interpolations methods available in the ArcGIS module, Spatial Analyst.

In the next steps, several vector data layers have to be prepared (Figure 4). These layers include information such as the course of the main stream, bank positions, approximated direction of flows in the floodplains, and location of cross-sections. The model prepared reconstructs $18,906.29 \mathrm{~m}$ of the river course. The geometry is represented by 99 cross-sections. The average distance between cross sections is about $250-300 \mathrm{~m}$. The distances of cross sections are smaller near bridges and structures.

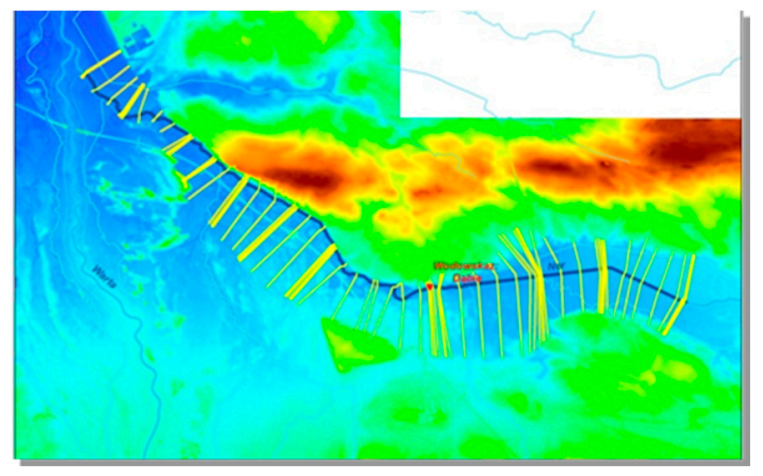

(a)

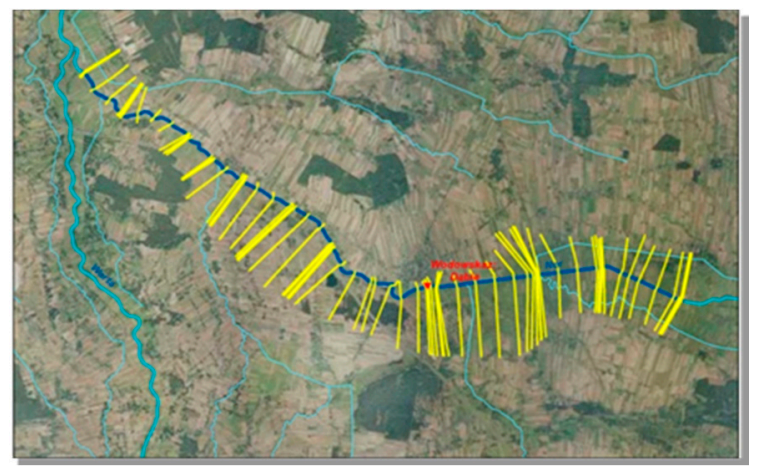

(b)

Figure 4. The river and the model cross-sections shown in (a) Digital Terrain Model (DTM) and (b) ortophotomap.

Simulations of flow and sediment transport were realized using HEC-RAS 5.0.1. The geometry of the model, including cross-sections of the riverbed and floodplains, is imported to HEC-RAS using standard SDF files (English: SDF = Standard Data Format). Such files are generated by the GeoRAS extension of ArcGIS on the basis of DTM and the vector layers described earlier. The flow module of the model is initially calibrated implementing (1) water surface elevations from the flood hazard maps of the ISOK project [23] and (2) maximum flows obtained from IMGW PIB (Polish: IMGW PIB = Instytut Meteorologii i Gospodarki Wodnej-Państwowy Instytut Badawczy, English: Institute of Meteorology and Water Management-National Research Institute). The set of maximum flows tested include 10-, 100- and 500-year floods. Such a set of flows was taken as the basis of the ISOK project [23] and it is very common in scientific works [28]. They correspond to probabilities of exceedance of $10 \%$, $1 \%$, and $0.2 \%$, respectively. Hence, they are denoted $Q_{10}, Q_{1}$, and $Q_{0.2}$ (Table 1$)$. During calibration, the steady flow module is used. Such an approach is consistent with the main assumptions behind the derivation of the equations describing the dynamics of channel flow [16]. The changes in flow resulting from increase in the catchment area are also taken into account. The main idea applied is to set roughness coefficients in such a way that the computed water elevations fit the elevations taken from the ISOK project. The measures used to assess the calibration quality are as follows:

Average absolute difference:

$$
M_{\text {mod }}=\frac{1}{N} \sum\left|W S_{\text {sim }}-W S_{\text {ISOK }}\right|
$$


Average square difference:

$$
M_{s q}=\frac{1}{N} \sqrt{\sum\left(W S_{s i m}-W S_{I S O K}\right)^{2}}
$$

Maximum absolute difference:

$$
M_{\max }=\max \left|W S_{\text {sim }}-W S_{I S O K}\right|
$$

where $W S_{\text {sim }}$-is the simulated water surface elevations, $W S_{I S O K}$ - the water surface elevations obtained from flood hazard maps. The marching form of the algorithm for steady flow computations implemented in HEC-RAS [17] enables decomposition of the problem. The roughness coefficients search for reaches between the locations of ISOK values of water elevation, from downstream to upstream.

Table 1. Measures of calibration quality.

\begin{tabular}{cccc}
\hline Measures of Calibration Quality $(\mathbf{c m})$ & $Q_{\mathbf{1 0}}$ (10 Year) & $Q_{\mathbf{1}}$ (100 Year) & $Q_{\mathbf{0 . 2}}$ (500 Year) \\
\hline - average absolute difference & 13.2 & 22.0 & 24.7 \\
- average square difference & 2.7 & 4.2 & 4.6 \\
- maximum absolute difference & 39.0 & 53.0 & 62.0 \\
\hline
\end{tabular}

The obtained fitting of simulated surface elevation, and those taken from flood hazard maps, are presented in Table 1. The results obtained are in agreement with reasonable expectations regarding the quality of the simulation model. The values of selected measures vary relatively slightly, if we take the complexity of real data used in the analyses into account. The values of average square differences $\left(M_{s q}\right)$, which is the most popular indicator of model quality, vary from 2.7 to $4.6 \mathrm{~cm}$. The values of average absolute difference $\left(M_{\text {mod }}\right)$ are greater, from 13.2 to $24.7 \mathrm{~cm}$. The maximum absolute differences $\left(M_{\max }\right)$ are used here for control and they vary from 39.0 to $62.0 \mathrm{~cm}$. The values of calibrated roughness coefficients vary from 0.012 to $0.035 \mathrm{~s} \cdot \mathrm{m}^{-1 / 3}$ in the river channel, and from 0.045 to $0.050 \mathrm{~s} \cdot \mathrm{m}^{-1 / 3}$ in floodplains.

The main simulation model is constructed on the basis of sediment transport module available in the HEC-RAS package. Simulation of morphodynamic changes in the riverbed consists of a few basic elements. These are: (a) calculation of quasi-unsteady flow; (b) numerical solution of the Exner equation implemented for particular fractions of sediment; and (c) proper sediment transport formulae enabling calculation of transport intensity. This module also includes several additional elements, e.g., an algorithm for updating bed elevations, procedures for the generation of resulting geometry, etc.

The fundamental element of the quasi-unsteady flow simulation is the solution of Bernoulli's equation $[16,29,30]$ in the form presented by Brunner [17]. The equation has a simple mathematical form of mechanical energy balance in fluid flow including: (1) potential energy; (2) work of pressure force; (3) kinetic energy; and (4) energy losses due to friction and cross-section contraction or expansion. In the form applied in HEC-RAS, the effects related to floodplains and compound shape of the channel are also taken into account. More detailed description of Equation (4) may be found in Brunner [17]. This concept enables determination of hydraulic parameters for steady flow conditions such as depth, average velocity, etc. There is one main assumption in the modeling of the quasi-unsteady flow with sediment transport. The hydraulic parameters are considered constant in some finite time intervals. This assumption enables the calculation of flow in the same way as for steady flow conditions. This approach means that we assume abrupt equalization of flow along the river reach. There is no flow propagation along a channel, which is the opposite to the modeling of unsteady flow with full St. Venant equations.

The sediment transport phenomena are modeled with Exner's equation [10,12,17]. The equation consists of two elements: (1) bed elevation changes and (2) gradient of total volumetric intensity of 
sediment transport. The second value is calculated with empirical formulae chosen for each sediment fraction separately.

Due to the fact that there is a lack of sufficient data for robust calibration of the sediment transport module, the approach based on sensitivity/uncertainty analysis is applied. The factors identified as most uncertain and affecting potential results are (1) empirical formula for sediment transport intensity; (2) grain size distribution, which is the main parameter of sediment transport formula. The third uncertain element in the entire predictive procedure is (3) future flow scenario. Hence, the approach applied here selects several forms of each factor and runs the model. The selection of the representative elements for uncertain factors is governed by statistical laws. The results obtained are also processed and presented as statistics.

Two empirical formulae for calculation of sediment transport are used: (1) the Meyer-Peter and Müller (MPM) formula; (2) Engelund-Hanasen (EH) formula. The first of them is a general relationship derived on the basis of laboratory experiments for coarse sediments like coarse sands and gravel $[9,10,13,31]$. Because of that, the MPM formula provides quite good results under mountainous conditions. However, its dimensionless form may suggest broader implementation. Some research on lowland rivers shows a satisfactory fit of the MPM formula with observations [13,32].

The second formula used, the Engelund-Hansen formula $[9,10,13,33,34]$, is addressed for rivers with sandy beds. The estimated characteristics of sediments in the analyzed Ner River reach fit this requirement.

The reference grain size distribution was selected as the approximate sieve curve reflecting a sandy bed, which is a typical kind of bed in the region where the Ner flows. Then several grain size distributions were generated as regular deviations from the reference one. During the preliminary tests, it occurred that the uncertainty of grain sizes is less important than two other factors, namely sediment transport formula and flow scenario. Hence, this element is neglected in further considerations.

The methods of statistical analysis used in this study $[35,36]$ are implemented at the stage of the data preparation as well as for post-processing of results. The statistical and probabilistic methods are used for the construction of flow scenarios, analysis of flow frequency, and their duration. For the simulation of sediment transport phenomena, 20 scenarios of a 10-year duration are constructed. The flow hydrographs are randomly selected from historical data for each scenario. At the stage of post-processing, the calculation of mean values, standard deviations, and scatter are crucial for proper interpretation of obtained results and uncertainty of formulated forecasts.

To take into account the uncertainty of the problem the computations are prepared in the way presented in Figure 5. The basic data, determined with satisfactory precision, are initial channel geometry and calibrated values of roughness coefficients. It is assumed that uncertainty of the forecast is mainly related to no possibility of knowing future flows, not knowing a proper formula for calculation of sediment transport intensity and incomplete information about grain size distribution. As previously mentioned, the last element occurred to be less important than the first two. The uncertainty of the future inflows is reconstructed by the selection of 20 scenarios of a 10-year duration. The uncertainty related to the calculation of sediment transport intensity is modeled by testing the two formulae described above, MPM and EH. All these elements with synthetic samples of sediments are used for the configuration of the simulation model. The model reconstructs the process of sediment transport with accumulation and erosion in the selected river reach. As the "inlet" boundary condition for Exner's equation the inflow of sediments in equilibrium conditions is imposed.

The results are 41 bed profiles. The first represents the initial bed; the rest include two sets of 20 profiles, which represent the final bed. Each set represents the effect of one sediment transport formula. Hence, a single result, the bed profile, depends on the implemented formula and flow scenario.

The bed profiles with flow frequency curves, maximum flows, and characteristic flows are used for configuration of the steady flow model. This model enables determination of water surface profiles and distribution along the channel of such hydraulic parameters as depth and flow velocity. The results depend mainly on the channel geometry and discharge. Such elements as roughness coefficients and 
outflow boundary condition are treated as known. The roughness is determined on the basis of previous simplified calibration of flow model. The boundary condition is imposed as free outflow (i.e., normal flow).

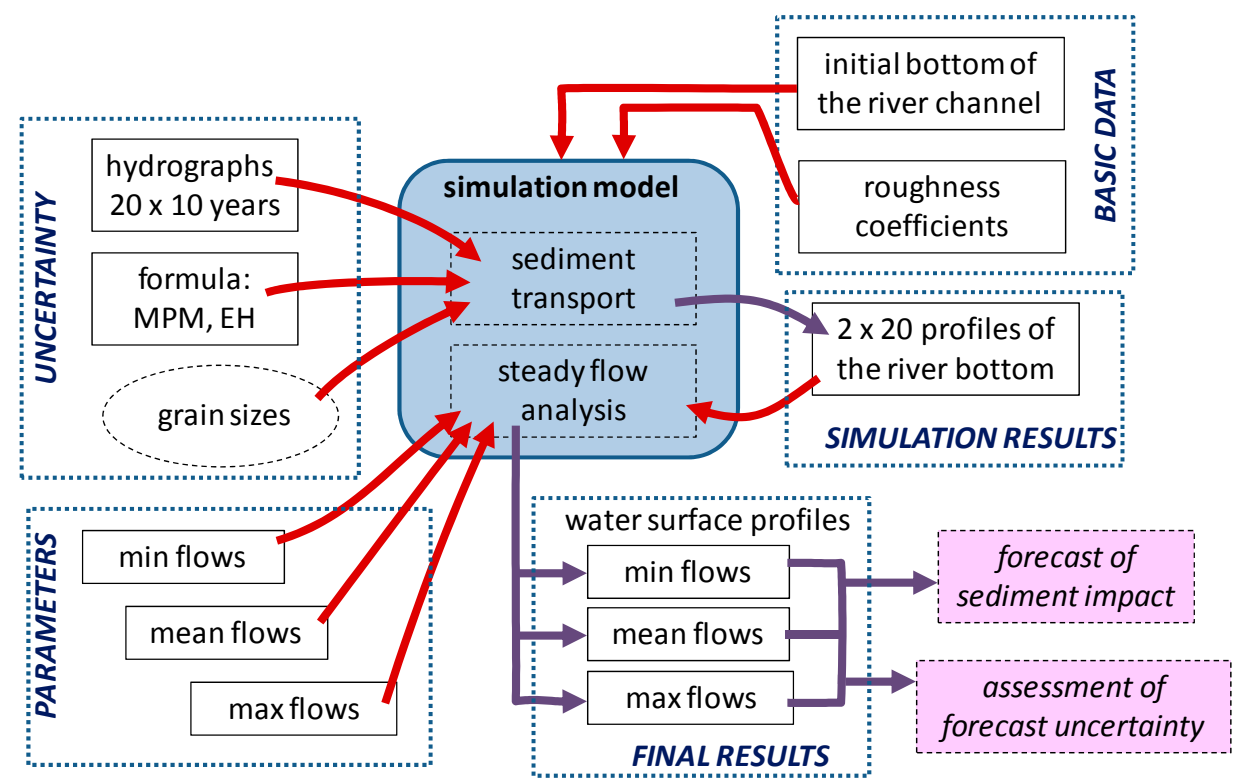

Figure 5. The basic idea of simulations.

The results of steady flow computations are water surface profiles corresponding to the minimum, mean, and maximum flows of the Ner River. These profiles are determined for each of the 41 beds obtained from sediment simulations. On the basis of these profiles, a comparison of initial and final simulated conditions can be made. The number of simulations and the analyzed variation of parameters enabled determination of the forecast uncertainty. The results may be also presented in the form of expected inundation frequency and its uncertainty. On this basis, flood hazard maps may also be produced, including expectations and possible deviations.

\section{Results and Discussion}

The first results are presented as longitudinal profiles of riverbed and water surface (Figures 6 and 7). There are initial and final results presented in each graph. The final geometry is the effect of averaging over results of simulations. The results of simulations are generated on the basis of 10-year flow scenarios. The averaging is performed for each sediment transport formula separately. The presented profiles are obtained for the average of mean flow determined for the period 1964-2013. The continuous lines represent the initial geometry. The dashed lines show the results for the final geometry. The black lines are bottoms and the blue ones are water surfaces.

In the case of the MPM formula (Figure 6), it is well seen that the sediments are accumulated mainly in the upper part of the channel. Completely different results are shown for the bed downstream of the bridge in the town of Dabie. There is relatively little or no accumulation. The changes in water surface follow the variation in bed positions. In the upper reach, the water surface is significantly increased. In the downstream reach, the water surface did not shift much from initial elevations.

The results obtained from simulation with the $\mathrm{EH}$ formula (Figure 7) are different. The accumulation of sediments is observed along the whole channel reach. The distribution of sediments is more uniform. The average increase in bottom elevations is about $1 \mathrm{~m}$. The changes in water surface elevations are similarly uniform. However, the changes in water surface are smaller than the rise in the bed. It may be noted that such uniform distribution of accumulated material is more compatible with earlier observations of bed changes in this river reach. Comparing with the results 
presented in Figure 3 and discussion in Section 2; the results obtained with the EH formula seem to be closer to real observations.

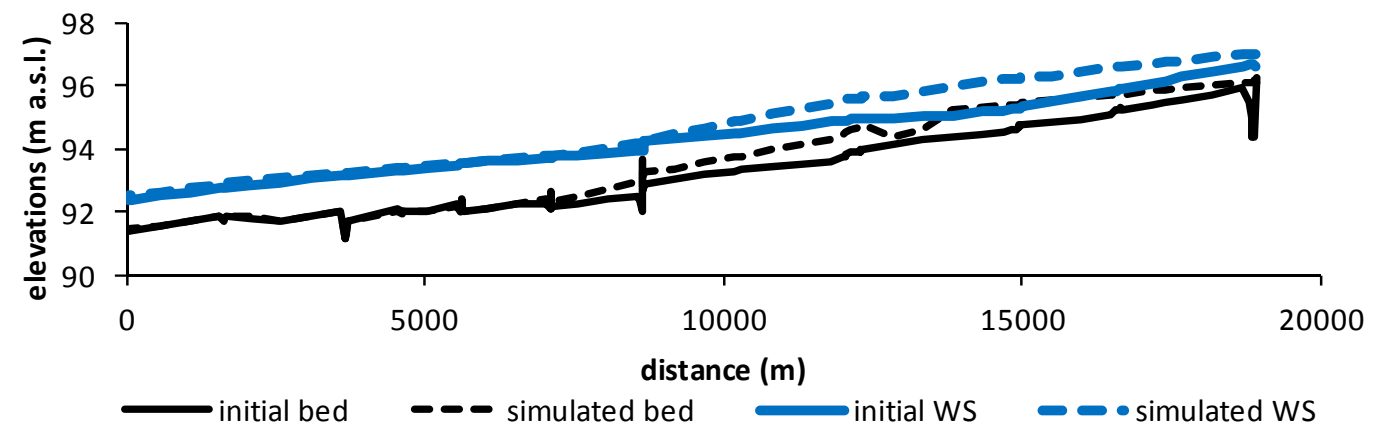

Figure 6. The averaged longitudinal profiles for mean flow in the Ner River calculated with the Meyer-Peter and Müller formula.

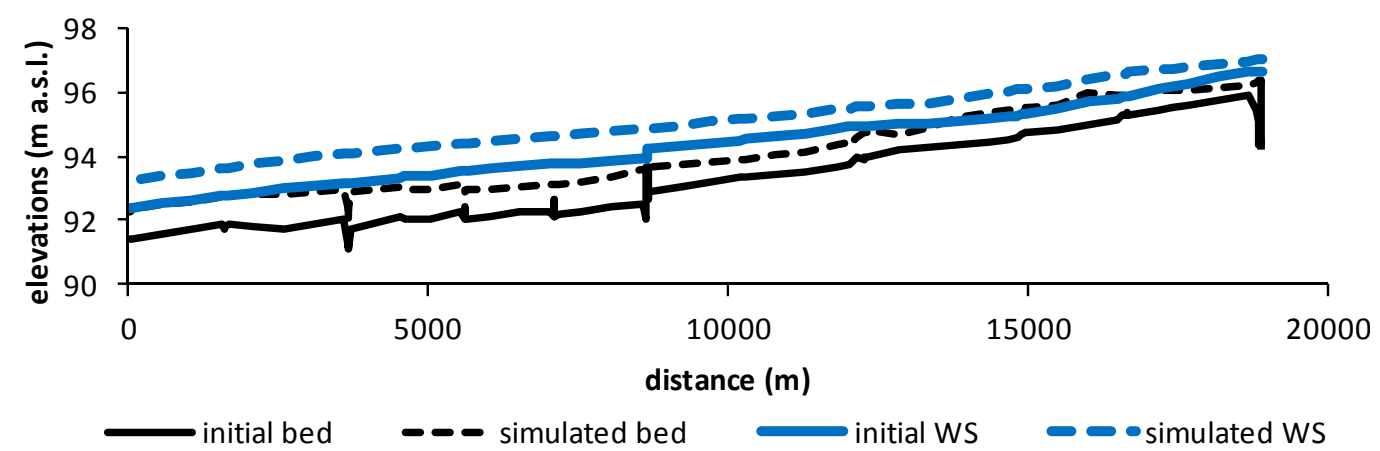

Figure 7. The averaged longitudinal profiles for mean flow in the Ner River calculated with the Engelund-Hansen formula.

The statistics of the sediment transport intensity in the inlet cross-section are shown in Figure 8. This graph characterizes the equilibrium load condition imposed as upstream boundary condition for the sediment transport equation. The red color is used to denote results obtained with the MPM formula. The blue-for the EH formula. The horizontal axis represents scenarios labeled with roman numbers. The bars, red and blue, show the values of median intensity of transport during each scenario. The variability of this measure is huge but the distribution of values in each scenario is not symmetrical. Hence, the quantiles 0.1 and 0.9 are used to characterize the variability. A value of the quantile 0.1 is too small to be visible in Figure 8. Only the second value is present, showing the practical range of variability. It is clear that the medians vary in the ranges of $0.60-0.80$ and $0.94-1.80 \mathrm{~kg} \cdot \mathrm{s}^{-1}$ for MPM and $\mathrm{EH}$, respectively. The quantiles estimated and the variability of calculated transport with $\mathrm{EH}$ are greater than those obtained with MPM. When the values of quantile 0.9 for the latter are below $5 \mathrm{~kg} \cdot \mathrm{s}^{-1}$, the same values for the former are beyond $10 \mathrm{~kg} \cdot \mathrm{s}^{-1}$ in many scenarios.

The graphs presented in Figures 9 and 10 show the changes in bed elevations obtained from simulations and their scatter, indicating the difference between maximum and minimum increments. The positive values indicate accumulation, negative-erosion. The averaged increments are presented as a blue line. The black lines show extreme values. The scatter for each cross-section is denoted as a red error bar. The dashed green line represents zero, what means no changes. Figure 9 shows results calculated with the MPM formula, Figure 10—the EH formula. 


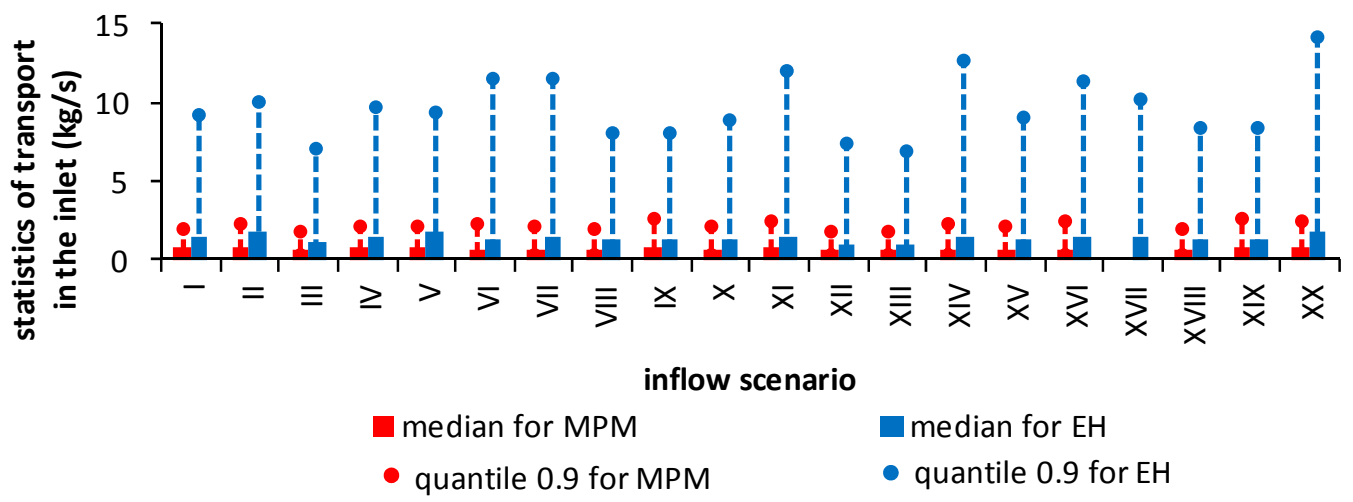

Figure 8. The statistics of sediment transport intensity in the inlet cross-section for both applied formulae.

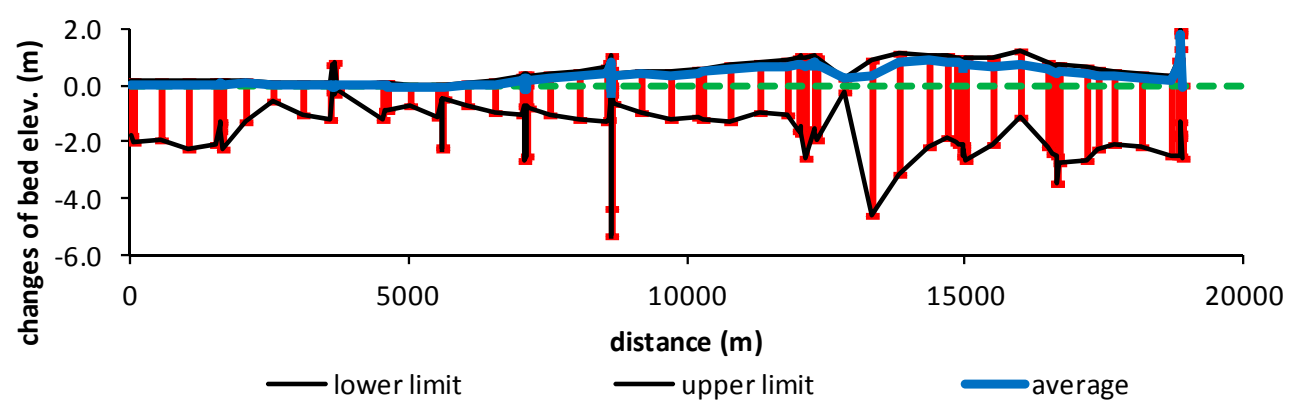

Figure 9. The changes in the average bottom elevation in the reach of the Ner River calculated with Meyer-Peter and Müller formula.

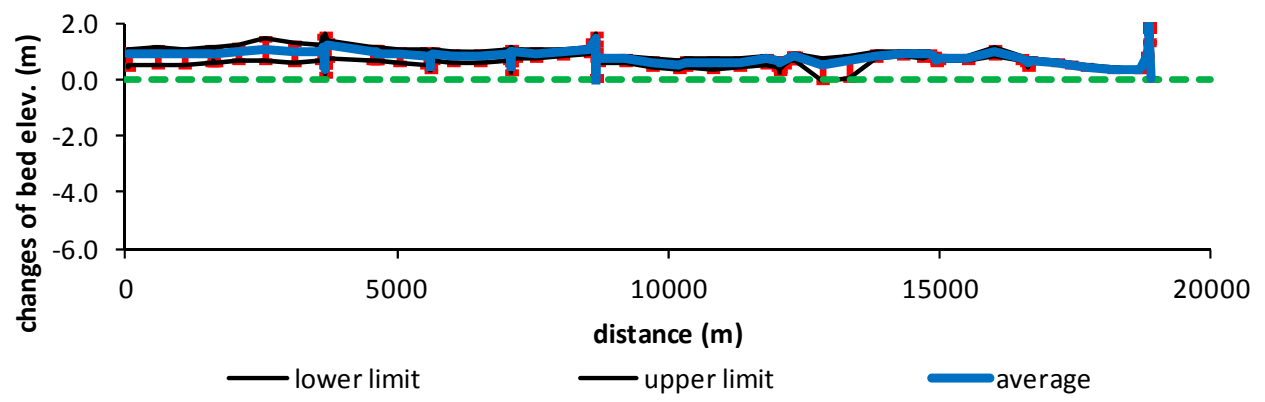

Figure 10. The changes of average bottom elevation in the reach of the Ner River calculated with Engelund-Hansen formula.

As shown in Figure 9, the scatter of values obtained with the MPM formula is quite considerable. In the upper reach it is about 5-6 $\mathrm{m}$. In the low part, downstream of the bridge in the town of Dabie, the scatter is smaller, varying from one to two meters.

Different tendencies are seen in the results obtained with the EH formula (Figure 10). The scatter of the values is significantly smaller and oscillates near half a meter. In the extreme case it reaches one meter. It is important to indicate that all results show accumulation of the sediments along the whole analyzed reach. This result is consistent with previous observations. These results permit making a more stable forecast. The subsequent simulations produce channel beds, which are more similar to others than when they were observed in the computations with MPM.

Changes in water surface elevations determined for the mean flow are shown in Figures 11 and 12. The first graph consists of results of simulations performed assuming the MPM formula, and the 
second with the $\mathrm{EH}$ formula. As previously mentioned, the blue line represents average changes and the black lines are extreme values, minimum and maximum. As expected, the changes in bottom elevations are not the same as those in the water surface elevations. The relationship between these two characteristics is indirect. The changes in the water surface elevations depend, not only on local increase or decrease in the bed, but also on the entire profile of the bed along the channel reach. Hence, the changes in the bed, downstream or upstream of a particular cross-section, may also affect the local water surface.

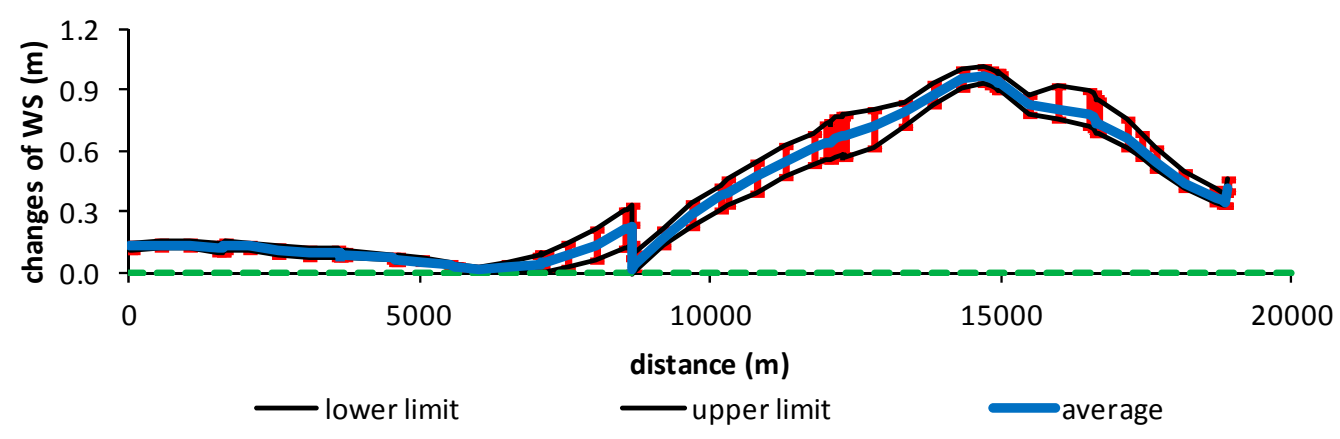

Figure 11. The changes in the water surface elevations for mean flow along the Ner River calculated with the Meyer-Peter and Müller (MPM) formula.

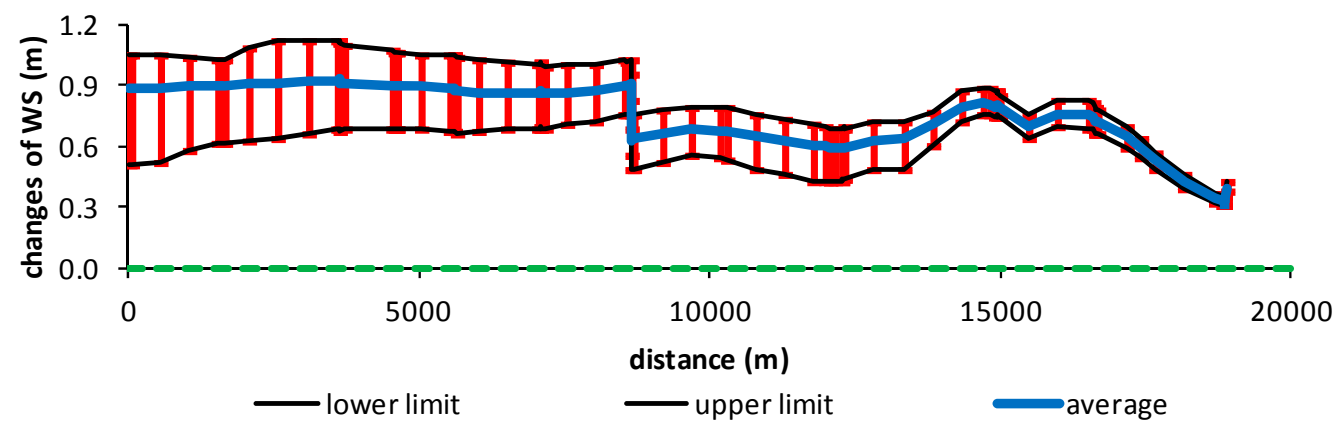

Figure 12. The changes in the water surface elevations for mean flow along the Ner River calculated with the Engelund-Hansen (EH) formula.

When the calculations are made with the MPM formula, the highest changes are clearly visible in the upper part of the reach. In this zone, the maximum increase in the water surface reaches one meter. In the downstream part, the maximum changes are about $30-40 \mathrm{~cm}$. It is important to note that the scatter of the results is small. Such results contrast with those representing the changes in the bed profile.

According to the results obtained with the $\mathrm{EH}$ formula, the highest changes in the water surface elevations are observed in the downstream part of the reach. They are about $90 \mathrm{~cm}$. However, the differences between the increases in the water surface in the downstream and upstream parts are smaller than those observed for the calculations with the MPM formula. In the upper part, the average increments are about $50 \mathrm{~cm}$. It should be pointed out that the scatters, marked as red error bars, are significantly higher than those following from the implementation of the MPM formula. They are about $50 \mathrm{~cm}$ in the downstream part and about $30 \mathrm{~cm}$ in the upstream one.

The results obtained show that the impact of sediment accumulation on water surface elevation with mean flow may be about $0.5 \mathrm{~m}$. This value is comparable with the impact of other factors described in literature, such as climate change's impact on maximum flows and maximum water stages [37-39], inaccuracies in the DEM causing errors in the generation of flood hazard zones [40,41], etc. 
It should also be indicated that the stability of the obtained averaged elevations are satisfactory in both cases. The only doubts are related to relatively huge scatters obtained with the EH formula; the reason for this is supposedly the influence of the boundary conditions.

\section{Conclusions}

The applied model of the Ner River including flow and sediment processes is prepared on the basis of commonly available data. It is undoubtedly a great advantage of the presented methodology. The methodology applied is based on GIS, simulation models, and statistical analysis. Its main elements are a sediment routing model and hydrodynamic calculations. The main concept is to formulate a 10-year forecast of sediment deposition and erosion in the selected reach of the Ner River. The approach discussed takes into account uncertainty related to (1) unknown inflows and (2) the form of formula for calculation of sediment intensity. To cope with the problem of unknown inflows, 20 scenarios of 10-year duration are composed on the basis of historical hydrographs. The problem of proper calculation of sediment transport intensity is solved by testing of two formulae, namely (1) Meyer-Peter and Müller (MPM) and (2) Engelund-Hansen (EH). The bed geometries resulting from sediment transport simulations are then used for the calculation of hydraulic conditions for the average of annual mean flow. Finally, the results are compared. On this basis, the validity of the results is estimated and the possible impacts of the sedimentation on water surface profiles are assessed.

There are significant differences in the obtained results related mainly to the type of formula chosen for the calculation of sediment transport intensity. In both cases the deposition is the dominant process in the selected reach of the Ner River. According to the simulations with the MPM formula, the material is non-uniformly distributed along the channel. The uncertainty related to the inflow scenario is higher in this case. The simulations with the EH formula provided much more stable results, as the distribution of the deposits was more uniform. Such results are more compatible with the earlier observations of sedimentation process in the Ner River. Although the changes in the bed elevations also have an impact on the water surface profiles, the relation between these two characteristics is not obvious. The results of hydraulic computations on the basis of bed geometries resulting from sediment simulations are a little bit confusing. Greater non-uniformity of changes follow from the tests with MPM. The changes in the water surface elevations are more uniform when assuming the EH formula. However, the results obtained with MPM seem to be more stable than those with EH, taking into account only water surface. This observation is very interesting and opens ways for further investigation.

Taking into account the uncertainty of available data, the presented methodology enables assessment of potential impact of sedimentation on the magnitude and distribution of water stages. It also enables estimation of sedimentation and channel capacity changes, and their influence on flood hazard and other threats. It seems to be really important to consider the impact of such processes as sediment accumulation and removal in long-term water management of rivers.

Author Contributions: Tomasz Dysarz, Ewelina Szałkiewicz and Joanna Wicher-Dysarz contributed equally in the work and in the production of the present manuscript.

Conflicts of Interest: The authors declare no conflicts of interest.

\section{References}

1. Wang, X.H.; Andutta, F.P. Sediment Transport Dynamics in Ports, Estuaries and Other Coastal Environments; Sino-Australian Research Centre for Coastal Management: Canberra, Australia, 2013.

2. Michalec, B. Selected methods for determination of suspended sediment transport. In Infrastructure and Ecology of Rural Areas; Monograph; Polish Academy of Sciences Cracow division: Cracow, Poland, 2009. (In Polish)

3. Michalec, B. The Use of Modified Annandale's Method in the Estimation of the Sediment Distribution in Small Reservoirs-A Case Study. Water 2014, 6, 2993-3011. [CrossRef] 
4. Michalec, B. Evaluation of an Empirical Reservoir Shape Function to Define Sediment Distributions in Small Reservoirs. Water 2015, 7, 4409-4426. [CrossRef]

5. Schleiss, A.J.; Franca, M.J.; Juez, C.; De Cesare, G. Reservoir sedimentation. J. Hydraul. Res. 2016, 54, 595-614. [CrossRef]

6. Afan, H.A.; El-shafie, A.; Mohtar, W.H.M.W.; Yaseen, Z.M. Past, present and prospect of an Artificial Intelligence (AI) based model for sediment transport prediction. J. Hydrol. 2016, 541, 902-913. [CrossRef]

7. Mohammad, M.E.; Al-Ansari, N.; Issa, I.E.; Knutsson, S. Sediment in Mosul Dam reservoir using the HEC-RAS model. Lakes Reserv. Res. Manag. 2016, 21, 235-244. [CrossRef]

8. Dutta, S.; Sen, D. Sediment distribution and its impacts on Hirakud Reservoir (India) storage capacity. Lakes Reserv. Res. Manag. 2016, 21, 245-263. [CrossRef]

9. Yang, C.T. Sediment Transport: Theory and Practice; McGraw-Hill Companies, Inc.: New York, NY, USA, 1996.

10. Parker, G. 1D Sediment Transport Morphodynamics with Applications to Rivers and Turbidity Currents. In E-book Available at Gary Parker's Morphodynamics Web Page; University of Illinois: Champaign, IL, USA, 2004; Last Update 13 April 2006; Available online: http:/ /hydrolab.illinois.edu/people/parkerg/ (accessed on 1 November 2016).

11. Popek, Z. Bedload Transport Conditions in Small Lowland River; Treatises and Monographs No. 300; Warsaw University of Life Sciences-SGGW: Warszawa, Poland, 2006; p. 230. (In Polish)

12. Wu, W. Computational River Dynamics; Taylor \& Francis Group: London, UK, 2007.

13. Radecki-Pawlik, A. Hydromorphology of Mountain Rivers and Streams; Selected Topics; Publishing of Cracow University of Agriculture: Cracow, Poland, 2014. (In Polish)

14. Ozga-Zielińska, M. Methods for Description and Analysis of Hydrological Systems; Publishing of Warsaw University of Technology: Warsaw, Poland, 1976. (In Polish)

15. Łapuszek, M.; Lenar-Matyas, A. Research on bed sediments in selected cross-sections of the Przemsza river and its main tributaries. In Infrastructure and Ecology of Rural Areas 2015/I; Polish Academy of Sciences, Cracow division: Cracow, Poland, 2015. (In Polish)

16. Szymkiewicz, R. Numerical Modeling in Open Channel Hydraulics. In Water Science and Technology Library; Springer: Dordrecht, The Netherlands, 2010; Volume 83.

17. Brunner, G.W. HEC-RAS River Analysis System Hydraulic References Manual; Report No. CPD-69; US Army Corps of Engineers: Washington, DC, USA; Hydrologic Engineering Center (HEC): Davis, CA, USA, 2010.

18. Bieżanowski, W. Łódka and other rivers of the Łódź city. In Library of Society for Care on Historic Monuments in the Łódź City; Widzew Publishing House ZORA: Łódź, Poland, 2001. (In Polish)

19. Penczak, T.; Kruk, A.; Grabowska, J.; Śliwińska, A.; Koszaliński, H.; Zięba, G.; Tybulczuk, S.; Galicka, W.; Marszał, L. Influence of gradual improvement in water quality on the regeneration of fish fauna in the Ner River. In Scientific Annual of the PAA; PZW: Warsaw, Poland, 2010; Volume 23, pp. 97-117. (In Polish)

20. Kondracki, J. Regional geography of Poland; PWN: Warsaw, Poland, 2002. (In Polish)

21. Szałkiewicz, E. Simulations of Flow and Sediment Transport for the Reach of the Ner River with Application of GIS Tools. Master's Thesis, Poznan University of Life Sciences, Poznan, Poland, 2015. (In Polish)

22. Wicher-Dysarz, J.; Dysarz, T. Influence of mud removal on hydraulic condition in the Ner River. Acta Sci. Pol. F. Circumiectus 2010, 9, 75-82. (In Polish)

23. ISOK Project. Cross-Sections Measured for Implementation of EU Flood Directive. Available online: http:/ / www.isok.gov.pl/pl/ (accessed on 8 November 2016). (In Polish)

24. CODGi. Geodesic and Cartographic Documentation Center. Available online: http://www.codgik.gov.pl/ (accessed on 8 November 2016). (In Polish)

25. Booth, B.; Mitchell, A. Getting Started with ArcGIS. Available online: http://webfacstaff.sas.upenn.edu/ $\sim$ dromano/classes/gis/files/Getting_Started_with_ArcGIS.pdf (accessed on 24 October 2016).

26. Cameron, T.; Ackerman, P.E. HEC-GeoRAS GIS Tools for Support of HEC-RAS Using ArcGIS User's; Manual; Report No. CPD-83; US Army Corps of Engineers: Washington, DC, USA; Hydrologic Engineering Center (HEC): Davis, CA, USA, 2012.

27. Brunner, G.W. HEC-RAS River Analysis System User's Manual Version 5.0. US Army Corps of Engineers; Report No. CPD-68; Hydrologic Engineering Center (HEC): Davis, CA, USA, 2016.

28. Barszcz, M.P. Analysis of Probable Flows Based on the Rainfall-Runoff Model for Flood Scenarios: A Case Study of the Losse River Catchment (Germany). Pol. J. Environ Stud. 2016, 25, 1403-1413. [CrossRef] 
29. Puzyrewski, R.; Sawicki, J. Fundamentals of Fluid Mechanics and Hydraulics; PWN Scientific Publishing: Warsaw, Poland, 2013. (In Polish)

30. Sawicki, J. Flows with Free Surface; PWN Scientific Publishing: Warsaw, Poland, 1998. (In Polish)

31. Meyer-Peter, E.; Müller, R. Formulas for bed-load transport. In Proceedings of the 2nd Meeting of the International Association for Hydraulic Structures Research, IAHR, Stockholm, Sweden, 7-9 June 1948; pp. 39-64.

32. Bartnik, W. Hydraulics of streams with moveable beds. Initiation of sediment movement. In Scientific Editions of the University of Agriculture in Krakow; Monograph No. 171; University of Agriculture in Krakow: Cracow, Poland, 1992; pp. 61-67. (In Polish)

33. Engelund, F.; Hansen, E. A Monograph on Sediment Transport in Alluvial Streams; Teknish Forlag, Technical Press: Copenhagen, Denmark, 1972.

34. Engelund, F.; Hansen, E. Hydraulic resistance in alluvial streams. J. Hydraul. Divis. 1966, 92, 315-326.

35. Chow, V.T.; Maidment, D.; Mays, L. Applied Hydrology. McGraw-Hill Series in Water Resources E Environmental Engineering; McGraw-Hill Science/Engineering/Math: New York, NY, USA 1988.

36. Ozga-Zielińska, M.; Brzeziński, J. Applied Hydrology; PWN Publishing: Warsaw, Poland, 1997. (In Polish)

37. Romanowicz, R.J.; Kiczko, A.; Osuch, M. Derivation of flood risk maps: Theory and practice. In Proceedings of the National Hydrological Conference, Monographic. Mądralin, Poland, 17-21 May 2010; Volume 68, pp. 337-346. (In Polish)

38. Jung, Y. Uncertainty in Flood Inundation Mapping. Ph.D. Thesis, Purdue University Graduate School, Purdue, IN, USA, 2011. Available online: http://docs.lib.purdue.edu/dissertations/AAI3507254/ (accessed on 8 November 2011).

39. Beven, K.; Leedal, D.; McCarthy, S.; Lamb, R.; Hunter, N.; Keef, C.; Bates, P.; Neal, J.; Wicks, J. Framework for Assessing Uncertainty in Fluvial Flood Risk Mapping; Research Report SWP1.7.; Flood Risk Management Research Consortium: Lancaster, UK, 2011.

40. Alho, P.; Hyyppä, H.; Hyyppä, J. Consequence of DTM Precision for Flood Hazard Mapping: A Case Study in SW Finland. Nord. J. Surv. Real Estate Res. 2009, 6, 21-39.

41. Hosein, T. Alluvial Fan Flood Hazard Assessment Based on DTM Uncertainty. Master's Thesis, International Institute for Geo-information Science and Earth Observations, Enschede, The Netherlands, 2010. Available online: https://www.itc.nl/library/papers_2010/msc/aes/hosein.pdf (accessed on 8 November 2016).

(C) 2017 by the authors. Licensee MDPI, Basel, Switzerland. This article is an open access article distributed under the terms and conditions of the Creative Commons Attribution (CC BY) license (http:/ / creativecommons.org/licenses/by/4.0/). 